\title{
Fulminant hepatic failure bridged to liver transplantation with molecular adsorbent recirculating system: a single center experience
}

\author{
Cataldo Doria MD \\ Jefferson Medical College and Thomas Jefferson University Hospital, Philadelphia \\ Lucio Mandala MD \\ Istituto Mediterraneo per i Trrapianti e Terapie ad Alta Specializzazione IsMeTT-UPMC, Palermo \\ Victor L. Scott MD \\ Maricopa Medical Center, Phoenix \\ Salvatore Gruttadauria MD

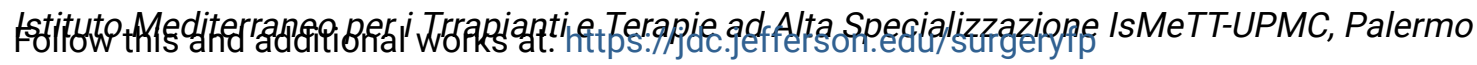

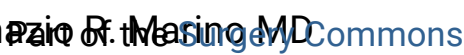

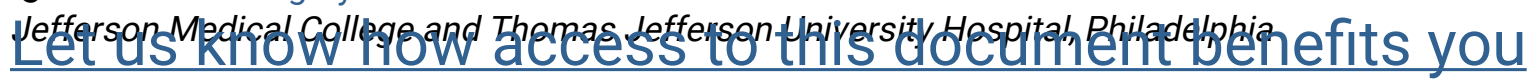

\section{Recommended Citation}

Doria, Cataldo MD; Mandala, Lucio MD; Scott, Victor L. MD; Gruttadauria, Salvatore MD; and Marino, Ignazio R. MD, "Fulminant hepatic failure bridged to liver transplantation with molecular adsorbent recirculating system: a single center experience" (2006). Department of Surgery Faculty Papers. Paper 1.

https://jdc.jefferson.edu/surgeryfp/1

This Article is brought to you for free and open access by the Jefferson Digital Commons. The Jefferson Digital Commons is a service of Thomas Jefferson University's Center for Teaching and Learning (CTL). The Commons is a showcase for Jefferson books and journals, peer-reviewed scholarly publications, unique historical collections from the University archives, and teaching tools. The Jefferson Digital Commons allows researchers and interested readers anywhere in the world to learn about and keep up to date with Jefferson scholarship. This article has been accepted for inclusion in Department of Surgery Faculty Papers by an authorized administrator of the Jefferson Digital Commons. For more information, please contact: JeffersonDigitalCommons@jefferson.edu. 
Fulminant hepatic failure bridged to liver transplantation with molecular adsorbent recirculating system: a single center experience

\section{CATALDO DORIA MD ${ }^{1}$, LUCIO MANDALA` MD $^{2}$, VICTOR L SCOTT, $\mathrm{MD}^{3}$, SALVATORE GRUTTADAURIA MD ${ }^{2}$, IGNAZIO R MARINO MD ${ }^{1}$}

From the Departments of Surgery, Anesthesiology, and Critical Care Medicine of the Istituto Mediterraneo per i Trapianti e Terapie ad Alta Specializzazione IsMeTT UPMC-Italy Palermo.

${ }^{1}$ Transplant Division, Department of Surgery, Jefferson Medical College Thomas Jefferson University Hospital, Philadelphia PA 19107, USA.

${ }^{2}$ Department of Surgery, Istituto Mediterraneo per $i$ Trapianti e Terapie ad Alta Specializzazione IsMeTT - UPMC Italy Palermo.

${ }^{3}$ Department of Anesthesiology, Maricopa Medical Center, Phoenix, AZ 85008 USA.

Correspondence Address:

Cataldo Doria MD, Assistant Professor of Surgery, Associate Director Transplant Division, Jefferson Medical College - Thomas Jefferson University Hospital, 1025 Walnut Street, Suite 605 College Building, Philadelphia, PA 19107, Telephone: (215) 955-8708, Fax: (215) 923-1420, e-mail: cataldo.doria@jefferson.edu Running head: $\quad$ MARS, a safe bridge to liver transplantation 


\section{ABSTRACT}

Purpose: We herein describe the clinical course of a consecutive series of fulminant hepatic failure patients treated with molecular adsorbent recirculating system, a cell-free albumin dialysis technique.

From November 2000 to September 2002, 7 adult patients age 22-61 (median 41), one male $(14.2 \%)$, and 6 females $(85.7 \%)$, affected by fulminant hepatic failure, underwent 7 courses (1 to 5 session each, six hours in duration) of extracorporeal support using the molecular adsorbent recirculating system technique. Pre and post treatment blood glucose, liver function tests, ammonia, arterial lactate, electrolytes, hemodynamic parameters, arterial blood gases, liver histology, Glasgow Coma Scale, and coagulation studies, were reviewed. No adverse side effects like generalized bleeding on non-cardiogenic pulmonary edema, often seen during MARS treatment, occurred in the patients included in this study.

Results: Six patients $(85.7 \%)$ are currently alive and well, and one (14.2\%) died. Four patients (57\%) were successfully bridged (two patients in 1 day and two other patients in 4 days) to liver transplantation, while $2(28.5 \%)$ recovered fully without transplantation. All the measured variables stabilized after molecular adsorbent recirculating system commencement. No differences were noted between the pre and post molecular adsorbent recirculating system liver histology. 
Conclusions: Molecular adsorbent recirculating system is a safe, temporary life support mechanism for patients awaiting liver transplantation or recovering from fulminant hepatic failure.

Key words: $\quad$ Albumin, dialysis, extracorporeal liver assist device, fulminant hepatitis 


\section{INTRODUCTION}

Molecular adsorbent recirculating system (MARS) (Teraklin, Aktiengesellschaft, Rostok, Germany) is an artificial liver support system, first introduced into clinical practice in 1993 [1]. In contrast to bio-artificial liver support systems, which replace some of the metabolic and synthetic functions of the liver by means of established hepatocyte or hepatoblastoma cell lines [2], MARS aims only at clearing the blood from metabolic waste products normally metabolized by the liver. It is, essentially, a modified dialysis system, employing an albumincontaining dialysate that is recirculated and perfused in-line through charcoal and anion exchanger columns. This effects the removal of albumin-bound toxins like aromatic amino acids and their metabolites, conjugated bilirubin, bile acids, phenols, short and middle chain fatty acids, copper, mercaptans, cytokines, tryptophan, tumor necrosis factor- $\alpha$, interleukin-6, and diazepam together with free solutes like ammonia, creatinine, urea that are removed by standard dialysis $[1,3]$. Most of the experience with MARS has shown specific efficacy in the treatment of acute-on-chronic hepatic failure, where it improves cerebral blood flow, hemodynamic status, liver and renal function, survival [4-6], and intractable pruritus [7]. Molecular adsorbent recirculating system maintains electrolytes homeostasis [8] may worsen coagulopathy [9] and be the cause non-cardiogenic pulmonary edema [10]. 
Fulminant hepatic failure (FHF) is defined as acute encephalopathy and coagulopathy in the setting of acute liver disease where altered mental status develops within 8 weeks from the onset of the illness in a person without antecedent liver disease [11]. Mortality rate in course of acuteliver failure is reported to be greater than 70\% [12-13]. Liver transplantation (LTx) is a well accepted therapy for FHF [14]. However, due to lack of organ availability it is not always possible to transplant patients with FHF. Therefore, several different types of supporting systems (artificial liver/bio-artificial liver) have been developed to bridge these patients to LTx or, if possible promote spontaneous recovery $[2,15-20]$. Molecular adsorbent recirculating system has been used in course of FHF [21]; however, changes in liver histology and its correlation with Glasgow Coma Scale (GCS) and prothrombin time, the two major clinical indicator of disease progression, have not been addressed before.

Fulminant hepatic failure is characterized by several biochemical derangements such as acidosis [12], hypophosphatemia, and hypoglycemia [22]. The degree of these derangements is, at least theoretically, related to the grade of liver necrosis. Trans-jugular liver biopsy is the method of choice to obtain liver tissue for histology in patients with FHF and to quantitate the degree of liver injury [23]. 


\section{METHODS}

Data were retrospectively collected from a consecutive series of patients admitted at the Istituto Mediterraneo per i Trapianti e Terapie ad Alta Specializzazione Palermo-Italy, from November 2000 to September 2002, with FHF who underwent MARS while awaiting LTx or recovery. Follow-up: 1155 days, range 455-1155 days. Informed consent, for MARS treatment and LTx, was obtained from next of kin.

Seven adult patients (numbered \#1 to \#7), one male (14.2\%) and 6 females (85.7\%), age $22-61$ years (median 41 years), underwent 7 courses ( 1 to 5 session each) of MARS. Demographics are shown in Table 1.

Patient \#1 developed fulminant hepatitis B. The patient was emergently transported to our center in stage 4 coma (Fig. 1) and died of brain herniation a few hours before LTx.

Hepatitis B Virus (HBV) was the cause of FHF in patient \# 2. The patient was emergently transported to our center in stage 3 coma (Fig. 1) and underwent the first LTx 5 days after the admission. The patient developed primary-non-function and 2 days later was successfully re-transplanted. She is alive and well 38 months after the second LTx.

Patient \# 3 developed drug related (nimesulide) FHF. The patient was emergently transported to our center awake and alert but 24 hours later went on to stage 3 
coma (Fig. 1). She was successfully transplanted 2 days following admission to our facility. She is alive and well 24 months after LTx.

Patient \# 4 developed HBV related FHF. The patient was emergently transported to our center awake and alert and remained so, despite $95 \%$ of liver necrosis, until the transplant, which occurred 2 days after the admission. This patient is alive and well 23 months after LTx.

Patient \# 5 developed HBV related FHF. The patient was emergently transported to our center in stage 3 coma, underwent two LTx during the same procedure, 5 days after the admission. The first graft, a very marginal one, accepted on an emergency base, underwent primary-non-function immediately after reperfusion, with about $80 \%$ hepatocyte necrosis. A second cadaveric donor became available at the time of the reperfusion of the first graft. She was, therefore, immediately re-transplanted. She is alive and well 18 months after LTx.

Patient \# 6 developed HBV related FHF. She underwent 4 MARS treatments before showing clinical recovery from the acute event. Due to her dramatic clinical improvement following the first MARS treatment and despite 50\% necrosis at the trans-jugular liver biopsy a decision was taken not to proceed with the transplant. She is alive and well 16 months after the last MARS session. Patient \# 7 developed HBV related FHF. He was never placed on the waiting list for LTx because he was diagnosed with colon cancer 12 months prior to his evaluation. The patient was emergently transported to our center in stage 3 coma 
and underwent a total of 5 MARS treatments before showing clinical amelioration. He is alive and well 15 months after the last MARS session. Our pre-transplant work-up includes trans-jugular liver biopsy for those patients fulfilling the O'Grady criteria for FHF [11] at the hospital presentation. In fact emergent listing for LTx and treatment with MARS, while waiting for LTx, was prompted for those patients showing $50 \%$ or more liver necrosis at liver histology.

Exclusion criteria from MARS and/or LTx candidacy were culture-proven sepsis and/or $<50 \%$ liver necrosis. In the intensive care unit, before starting MARS, full patient monitoring was instituted including: central venous pressure, SwanGanz catheter placement, and systemic arterial line. Due to onsite unavailability of technical expertise in positioning epidural probes for intracranial pressure monitoring, this parameter was not followed.

Each course of MARS was intended to consist of seven treatment sessions, six hours in duration (none of them had to be terminated in advance), on consecutive days. However, none of the patients completed the prescribed course ( 7 sessions) due to transplantation, death or significant clinical improvement. If a liver became available while the patient was on MARS, the transplant was started after the 6 hours session was completed. 
Molecular adsorbent recirculating system was performed through a hemodialysis double-lumen catheter, as previously described [24]. Priming of the extracorporeal circuit with heparinized saline solution $(1,000 \mathrm{U}$ of heparin sulphate / liter) was carried out before MARS commencement. The extracorporeal blood circuit was driven by a standard dialysis machine (D-85716, Baxter, Unterschleibheim, Germany) at a flow rate of $100 \mathrm{ml} / \mathrm{min}$ initially, increased to $200 \mathrm{ml} / \mathrm{min}$ if the patient remained hemodynamically stable. The aim of this study was the assessment of the safety and efficacy of MARS in patients with FHF.

During MARS therapy all patients were closely monitored for disturbances in electrolytes, glucose level, coagulation, and blood gas exchanges. These derangements, if present, were treated as indicated.

Pre and post-MARS blood glucose, liver function tests (total bilirubin, aspartate aminotransferase, alanine aminotransferase, gamma-glutamyl transpeptidase), ammonia, arterial lactate, electrolytes (sodium, potassium, chloride, calcium, phosphorus, and magnesium as well as the ionized fraction of calcium and magnesium), hemodynamic parameters (systemic blood pressure, central venous pressure, pulmonary arterial pressures, cardiac output, cardiac index, systemic vascular resistance index), arterial blood gas, GCS, and coagulation studies (platelet count, prothrombin time, international standardized ratio), were used for comparison. 
Liver histology was used to quantitate the percentage of necrosis. Post-MARS liver histology on the native liver, obtained at the time of LTx, and percutaneous liver biopsies, performed after recovery from the acute event for patients \# 6 and \# 7 (those recovered without LTx), was used for comparison with pre-MARS liver histology. Patient \# 1 died before transplantation, autopsy consent was denied; therefore, post-MARS liver histology for patient \#1 was not available for this study.

Data are presented as mean \pm standard deviation. Blood samples for laboratory tests were collected immediately before and immediately after each MARS session.

\section{RESULTS}

Six patients (85.7\%) survived to be discharged from the hospital and they are all alive and well 15 months after the last MARS session. One patient (14.2\%) died of brain herniation while our team was recovering a liver from an organ donor. Four patients (57\%) were successfully bridged, using MARS, to LTx, and 2 $(28.5 \%)$ recovered fully without transplantation.

\section{Biochemical effect of MARS}

Pre and post MARS serum electrolytes concentration remained remarkably stable (data not shown). 
Hypoglycemia is common in FHF being due to altered gluconeogenesis in the failing liver with inadequate hepatic uptake of insulin, heading to increased peripheral insulin levels [22]. In our series patients treated with MARS showed remarkable stable blood glucose during treatments (data not shown).

Total bilirubin (Tab. 2), transaminases, gamma-glutamyl transpeptidase, and ammonia, as previously reported [1,3], all improved with MARS (data not shown).

Molecular adsorbent recirculating system reduced, in FHF, the arterial blood lactate level (Fig. 2).

$\underline{\text { Effect of MARS on mental status }}$

Those patients that recovered fully without LTx (patients \# 6, and 7 of table 1) showed a steady improvement in GCS after each MARS sessions (Fig. 1). Patient \# 5 of table 1, also, had a significant improvement in GCS after the first MARS session (Fig. 1); however, at the time of LTx liver necrosis was >95\% (Tab. 3). $\underline{\text { Hemodynamic effect of MARS }}$

Patients with FHF tend to be hemodynamically unstable with a low systemic vascular resistance index and a hyperdinamic circulation [30]. None of the patients treated in our series, required vasopressors infusion before transplantation and all remained hemodynamically stable throughout MARS treatment. Amelioration of the hyperdynamic state, was supported by elevation of systemic 
vascular resistance index, mean arterial pressure, and reduced cardiac index (Fig. $3)$.

\section{Effect of MARS on gas exchange}

Pre and post MARS blood gas remained remarkable stable (data not shown). Histological effect of MARS

No signs indicative of MARS affecting liver histology were noted when pre and post MARS liver specimens where compared in the patients who underwent LTx (Tab. 3: comparison is between histology at the time of the trans-jugular liver biopsy and histology on the explanted liver). Four out of 5 patients who underwent LTx showed at the trans-jugular liver biopsy $80 \%$ or more liver necrosis (Tab. 3). Patients \# 6 and \# 7 (those recovered without LTx) showed 50 $\%$ liver necrosis at the admission to the hospital and absence of necrosis at recovery following the last MARS treatment (Tab. 3).

\section{Effect of MARS on blood coagulations}

All patients were coagulophatic at admission and remained as such, despite aggressive medical correction throughout the stay in the intensive care unit, which consisted in continuous infusion of fresh frozen plasma at the rate of $30 \mathrm{cc} / \mathrm{h}$. Although one could postulate that the percentage of necrotic liver tissue correlates directly to all the commonly seen clinical and biochemical derangements of FHF, we did not find any relationship between necrosis and prothrombin time (Fig.4). Prothrombin time before and after MARS is reported in Figure 4. 


\section{DISCUSSION}

Paradoxically the major limitation for this study is the availability of LTx which occurs at various time after treatment commencement; therefore, causing difficulties in designing scientifically reproducible clinical trials We cannot exclude that some of our observed results, in terms of biochemical omeostasis/hemodynamic stability during treatment of FHF with MARS, may be secondary to aggressive medical management in the intensive care unit, preceding transplantation. However, there are proven effects, in different model, of MARS ameliorating parameters not otherwise influenced by medical therapy, such as total bilirubin [1, 3], and blood lactate levels [24]. The liver is the principal organ for lactate metabolism, accounting for $50 \%$ of whole body lactate clearance and utilization, and hence participates in the regulation of serum lactate concentrations [25-26]. Moreover, in the LTx literature, with both cadaveric and living donor, it has been demonstrated that the rate of lactate elimination after reperfusion of the transplanted liver, represents one of the most sensitive and reliable indicators of hepatic graft function [27-29]. Therefore, we believe that the decrease lactate level during MARS treatment of patients with FHF indicates improvement (Fig. 2). It is uncertain whether, in our series, MARS is responsible for the observed decreased transaminases, because normalization of liver enzymes in the late phase of FHF is typically seen after massive liver necrosis. 
However, it appears that the degree of liver necrosis, GCS, and timing in MARS commencement may play a role in the outcome of FHF.

In patient \# 5 we observed GCS improvement after MARS commencement (Fig. 1), despite ongoing liver necrosis (more then $95 \%$ in the explanted liver, table 2). The same was also observed in patients \# 6 and \# 7 (those recovered without LTx) (Fig. 1). We believe that the common denominator for these three patients was the $50 \%$ liver necrosis at the time of MARS commencement. During FHF, coma is the antecedent of brain herniation and the various degree of mental status changes observed are, in fact, strictly related to the amount of death liver cells and the consequent toxins load present in the blood stream $[11,22,27]$. There is multiple evidence that MARS is able to remove those toxins $[1,3]$; therefore based on our data, we postulate that if MARS is started before liver necrosis exceeds $50 \%$, brain herniation can be delayed.

A common criticism to trans-jugular liver biopsy in course of FHF is that it represents a random liver biopsy and as such it does not reflect the real percentage of liver necrosis present in the whole liver. However, $80 \%$ of the patients in our series who were transplanted (patients numbered 1 to 4 , table 3 ) showed a sensitive correlation between pre and post transplant amount of liver necrosis. Therefore, we believe that the percentage of liver necrosis seen at the transjugular liver biopsy should be used as a clinical guidance to transplantation. We did not expect any histological change after MARS because of the very few 
treatment sessions and the short time allowed between the histological observations. For other reasons (few MARS sessions and long interval between histological observations) we believe that the absence of necrosis in the postMARS liver histology for patients \# 6 and \# 7 was not a consequence of MARS treatment. It was expression of healing from FHF. Obviously, each patient of our series was treated with a different number of MARS sessions because suitable organ donors became available at different times during MARS treatment for the different patients. Nonetheless, in our small series, MARS was found to be safe and efficacious in maintaining stability in patients diagnosed with FHF and awaiting LTx. Our result suggest that MARS delayed central nervous system catastrophe by clearing the toxins load typical of FHF, thus allowing more time for successful bridging to LTx. 


\section{REFERENCES}

1. Stange J, Mitzner S, Ramlow W, Gliesche T, Hickstein H, Schmidt R: A new procedure for the removal of protein bound drugs and toxins. ASAIO J 39(3):M621-5, 1993

2. Jaregui HO: Cellular component of bioartificial liver support systems. Artif Organs 23(10):889-893, 1999

3. Mitzner SR, Stange J, Klammt S, Risler T, Erley CM, Bader BD, Berger ED, Lauchart W, Peszynski P, Freytag J, Hickstein H, Loock, J, Löhr JM, Liebe S, Emmrich J, Korten G, Schmidt R: Improvement of hepatorenal syndrome with extracorporeal albumin dialysis MARS: results of a prospective, randomized, controlled clinical trial. Liver Transpl 6(3):277-286, 2000

4. Sorkine P, Ben Abraham R, Szold O, Biderman P, Kidran A, Merchav H, Brill S, Oren R: Role of molecular adsorbent recycling system (MARS) in the treatment of patients with acute exacerbation of chronic liver failure. Crit Care Med 29(7):1332-1336, 2001

5. Schmidt LE, Svedensen LB, Sørensen VR, Hansen BA, Larsen FS: Cerebral blood flow velocity increases during a single treatment with molecular adsorbents recirculating system in patients with acute on chronic liver failure. Liver Transpl 7(8):709-712, 2001

6. Schmidt LE, Sørensen VR, Svedensen LB, Hansen BA, Larsen FS: Hemodynamic changes during a single treatment with the molecular 
adsorbents recirculating system in patients with acute-on-chronic liver failure. Liver Transpl 7(12):1034-1039, 2001

7. Doria C, Mandala ' L, Smith J, Vitale CH, Lauro A, Gruttadauria S, Marino IR, Scotti Foglieni C, Magnone M, Scott VL: Effect of MARS in HCVrelated intractable pruritus. Liver Transpl 9(4):437-443, 2003

8. Doria C, Doyle HR, Mandala` L, Marino IR, Caruana G, Gruttadauria S, Lauro A, Magnone M, Scotti Foglieni C, Lamonaca V, Scott VL: Changes in serum electrolytes during treatment of patients in liver failure with molecular adsorbent recirculating system. Int J Artif Organs 26(10):918-23, 2003

9. Doria C, Mandala` L, Smith J, Caruana G, Scott VL, Gruttadauria S, Magnone M, Marino IR: Thromboelastography used to assess coagulation during treatment with molecular adsorbent recirculating system. Clin Transplant 2004;18:367-371.

10. Doria C, Mandala` L, Scott VL, Marino IR, Gruttadauria S, Miraglia R, Vitale $\mathrm{CH}$, Smith J: Non-cardiogenic pulmonary edema induced by molecular adsorbent recirculating system. Case report. J Artif Organs 6(4):282-285, 2003.

11. O'Grady JG, Schalm SW, Williams R: Acute liver failure: redefining the syndromes. Lancet 342:273-5, 1993

12. O'Grady JG, Graeme JMA, Hayllar K, Williams R: Early indicators of prognosis in fulminant hepatic failure. Gastroenterology 97:439-45, 1989 
13. O’Grady JG, Gimson AES, O’Brien CJ, Pucknell A, Hughes RD, Williams $\mathrm{R}$ : Controlled trials of charcoal hemoperfusion and prognostic factors in fulminant hepatic failure. Gastroenterology 94:1186-92, 1988.

14. Van Thiel DH, Brems J, Nadir A, Idilman R, Colantoni A, Holt D, Edelstein S: Liver transplantation for fulminant hepatic failure. J Gastroenterol 37[Suppl XIII]:78-81, 2002

15. Yamazaki Z, Fujimori Y, Sanjo K, Kojimay Y, Sugiura M, Wada T, Inoue N, Sakai T, Oda T, Kominami N, Fujisaki U, Kataoka K: New artificial liver support system (plasma perfusion detoxification) for hepatic coma. 1978. Ther Apher 4(1):23-5, 2000

16. Hughes RD, Nicolau N, Langley PG, Ellis AJ, Wendon JA, Williams R: Plasma cytokine levels and coagulation and complement activation during use of the extracorporeal liver assist device in acute liver failure. J Artif Organs 22(10):854-858, 1998

17. Ting PP, Demetriou AA: Clinical experience with artificial liver support systems. Canadian Journal of Gastroenterology14[Suppl]D:79D-84D, 2000

18. Falkenhagen D, Strobl W, Vogt G, Schrefl A, Linsberger I, Gerner FJ, Schoenhofen M. Fractionated plasma separation and adsorption system: a novel system for blood purification to remove albumin bound substances. $\mathrm{J}$ Artif Organs 23(1):81-86, 1999 
19. Bismuth H, Figuerio J, Samuel D: What should we expect from a bioartificial liver in fulminant hepatic failure? J Artif Organs 22(1):26-31, 1998

20. Jalan R, Williams R: Bio-artificial liver support for acute liver failure: should we be using it to treat patients? Transplantation 73(2):165-166, 2002.

21. Steiner C, Mitzner S: Experiences with MARS liver support therapy in liver failure: analysis of 176 patients of the international MARS registry. Liver 22(Suppl. 2):20-25, 2002

22. Lee WM:Medical progress: acute liver failure. N Engl J Med 329(25):18621872,1993

23. McAfee JH, Keeffe EB, Lee RG, Rosch J: Transjugular liver biopsy. Hepatology 15(4):726-32, 1992

24. Stange J, Mitzner SR, Risler T, Erley CM, Lauchart W, Goehl H, Klammt S, Peszynski P, Freytag J, Hickstein H, Löhr M, Liebe S, Schareck W, Hopt UT, Schmidt R: Molecular adsorbent recycling system (MARS): clinical results of a new membrane-based blood purification system for bioartificial liver support. J Artif Organs 23(4):319-330, 1999

25. Buchalter S, Crain M, Kreisberg: Regulation of lactate metabolism in vivo. Diabetes Metab Rev 5(4):379-391, 1989

26. Kreisberg R: Lactate homeostasis and lactic acidosis. Ann Intern Med 92(2 Pt 1):227-237, 1980 
27. Fath JJ, Ascher NL, Konstantinided FN, Bloomer J, Sharp H, Najarian JS, Cerra FB: Metabolism during hepatic transplantation: indicators of allograft function. Surgery 96(4):664-674, 1984

28. De Gasperi A, Mazza E, Corti A, Zoppi F, Prosperi M, Fantini G, Scaiola A, Colella G, Amici O, Notaro P, Rocchini A, Ceresa F, Roselli E, Grugni MC: Lactate blood levels in the perioperative period of orthotopic liver transplantation. Int J Clin Lab Res 27(2):123-128, 1997

29. Orii R, Sugawara Y, Hayashida M, Yamada Y, Kubota K, Takayama T, Harihara Y, Makuuchi M, Hanaoka K: Peri-operative blood lactate levels in recipients of living-related liver transplantation. Transplantation 69(10):21242127,2000

30. Hoofnagle JH, Carithers Jr RL, Shapiro C, Ascher N: Fulminant hepatic failure: summary of a workshop. Hepatology 21(1):240-252, 1995 


\begin{tabular}{|c|c|c|c|c|c|c|c|c|c|c|}
\hline $\boldsymbol{N}$ & Sex/age & Diagnosis & $\begin{array}{l}\text { Outcome/\# of } \\
\text { MARS } \\
\text { sessions }\end{array}$ & $\begin{array}{l}\text { Follow- } \\
\text { up days }\end{array}$ & $\begin{array}{c}\text { Total } \\
\text { bilirubin } \\
\text { mg/dl }\end{array}$ & $\begin{array}{l}A S T \\
I U / L\end{array}$ & $\begin{array}{l}A L T \\
I U / L\end{array}$ & $\begin{array}{l}\gamma G T \\
I U / L\end{array}$ & $\begin{array}{l}\text { Albumin } \\
\text { gr. }\end{array}$ & $\begin{array}{l}P T \\
\%\end{array}$ \\
\hline 1 & $\mathrm{~F} / 30$ & FHF/HBV & Died/2 & 0 & 7.41 & 789 & 2223 & 44 & 3.5 & 28 \\
\hline 2 & $F / 29$ & FHF/HBV & $\begin{array}{c}\text { Alive- } \\
\text { transplanted/4 }\end{array}$ & 820 & 6.97 & 289 & 1120 & 25 & 3.4 & 28 \\
\hline 3 & $F / 22$ & $\begin{array}{c}\text { FHF/ } \\
\text { nimesulide }\end{array}$ & $\begin{array}{c}\text { Alive- } \\
\text { transplanted/1 }\end{array}$ & 393 & 13.13 & 209 & 254 & 48 & 3.8 & 30 \\
\hline 4 & $\mathrm{~F} / 51$ & FHF/HBV & $\begin{array}{c}\text { Alive- } \\
\text { transplanted/1 }\end{array}$ & 366 & 11.65 & 1239 & 1986 & 60 & 3 & 38.6 \\
\hline 5 & F/61 & FHF/HBV & $\begin{array}{c}\text { Alive- } \\
\text { transplanted/4 }\end{array}$ & 218 & 17.01 & 749 & 1519 & 51 & 3 & 39.6 \\
\hline 6 & $\mathrm{~F} / 41$ & FHF/HBV & Alive/4 & 184 & 9.94 & 455 & 1730 & 51 & 3.1 & 30 \\
\hline 7 & $\mathrm{M} / 50$ & FHF/HBV & Alive/5 & 180 & 12.08 & 638 & 2308 & 30 & 2.8 & 24.1 \\
\hline
\end{tabular}

Table 1: PATIENT AND LABORATORY DATA AT HOSPITAL ADMISSION

\section{Footnotes:}

AST: $\quad$ Aspartate aminotransferase.

ALT: $\quad$ Alanine aminotransferase.

$\quad$ GT: $\quad$ Gamma-glutamyl transpeptidase.

PT: $\quad$ Prothrombin time

FHF: $\quad$ Fulminant Hepatic Failure

HBV: Hepatitis B Virus 
Table 2: CHANGE IN TOTAL BILIRUBIN

\begin{tabular}{|c|c|c|c|c|c|}
\hline $\begin{array}{l}\text { Patient } \\
\text { number }\end{array}$ & $\begin{array}{c}\text { Pre-MARS } \\
\text { total } \\
\text { bilirubin } \\
\text { mg/dl }\end{array}$ & $\begin{array}{c}\text { Post-MARS } \\
\text { session \#1 } \\
\text { total } \\
\text { bilirubin } \\
\text { mg/dl }\end{array}$ & $\begin{array}{c}\text { Post-MARS } \\
\text { session \#2 } \\
\text { total } \\
\text { bilirubin } \\
\text { mg/dl }\end{array}$ & $\begin{array}{c}\text { Post-MARS } \\
\text { session \#3 } \\
\text { total } \\
\text { bilirubin } \\
\text { mg/dl }\end{array}$ & $\begin{array}{c}\text { Post-MARS } \\
\text { session \#4 } \\
\text { total } \\
\text { bilirubin } \\
\text { mg/dl }\end{array}$ \\
\hline 1 & 7.41 & 8.48 & 8.91 & 8.14 & 7.31 \\
\hline 2 & 6.97 & 8.33 & 7.88 & 6.78 & 6.72 \\
\hline 3 & 13.13 & 10.06 & 11.29 & - & - \\
\hline 4 & 11.65 & 10.83 & - & - & - \\
\hline 5 & 17.01 & 12.17 & - & - & - \\
\hline 6 & 9.94 & 8.10 & - & - & - \\
\hline 7 & 12.08 & 12.03 & - & - & - \\
\hline
\end{tabular}


Table 3: PRE AND POST MARS LIVER HISTOLOGY

\begin{tabular}{l|l|l} 
Patient number & Pre-MARS necrosis & Post-MARS necrosis
\end{tabular}

\begin{tabular}{|c|c|c|}
\hline 1 & $80 \%$ & $\mathrm{n} / \mathrm{a}$ \\
\hline 2 & $100 \%$ (massive) & $100 \%$ (massive) \\
\hline 3 & $95 \%$ & $90 \%$ \\
\hline 4 & $95 \%$ & $100 \%$ (massive) \\
\hline 5 & $50 \%$ & $09 \%$ (submassive) \\
\hline 6 & $50 \%$ & $0 \%$ \\
\hline 7 & $50 \%$ & $0 \%$ \\
\hline
\end{tabular}




\section{Correlation between GCS and necrosis during MARS}

\section{Figure 1 legend:}

Glasgow Coma Scale is represented by bars. The percentage of liver necrosis is represented by lines. Each group of bars refers to a single patient. The first bar, for each patient, identifies the pre-MARS GCS, the following bars of each group represent GCS after each MARS session up to three sessions. The line with a triangular dot represents the percentage of liver necrosis before MARS commencement. The line with the quadrate dot represent the percentage of liver necrosis on the explanted liver or (for patient \#6 and \# 7), at recovery after the acute event.

\section{Footnotes:}

GCS: $\quad$ Glasgow Coma Scale

MARS: $\quad$ Molecular Adsorbent Recirculating System

Pt: Patient

T: $\quad$ Treatment 


\section{Pattern of arterial lactate during MARS in FHF}

Figure 2 legend:

The $x$ axis represents the mean arterial lactate concentration in $\mathrm{mmol} / \mathrm{L}$, whereas the $y$ axis represents the different MARS sessions.

\section{Footnotes:}

MARS: $\quad$ Molecular Adsorbent Recirculating System

FHF: $\quad$ Fulminant Hepatic Failure 


\section{CO, CI and SVRI during MARS in FHF}

\section{Figure 3 legend:}

Mean cardiac output and cardiac index are represented by bars of different color. Their unit of measure is $\mathrm{L} / \mathrm{min}$ and is reported on the left side of the figure. Mean systemic vascular resistance index is represented by a line. Its unit of measure is dynes $/ \mathrm{cm} / \mathrm{m} 2$ and is reported on the right side of the figure. The first set of bars represents pre-MARS values, whereas the following sets represent post-MARS values from session 1 to 4 .

\section{Footnotes:}

CO: Cardiac output

CI: Cardiac index

SVRI: Systemic vascular resistance index 


\section{Correlation between PT and necrosis during MARS}

\section{Figure 4 legend:}

Bars represent pre and post-MARS percentage of liver necrosis whereas lines indicate the prothrombin time. The triangular dot represent pre-MARS prothrombin time, the $\mathrm{X}$ dot represent post-MARS prothrombin time.

\section{Footnotes:}

PT: $\quad$ Prothrombin Time

Pt: Patient

T: $\quad$ Treatment 


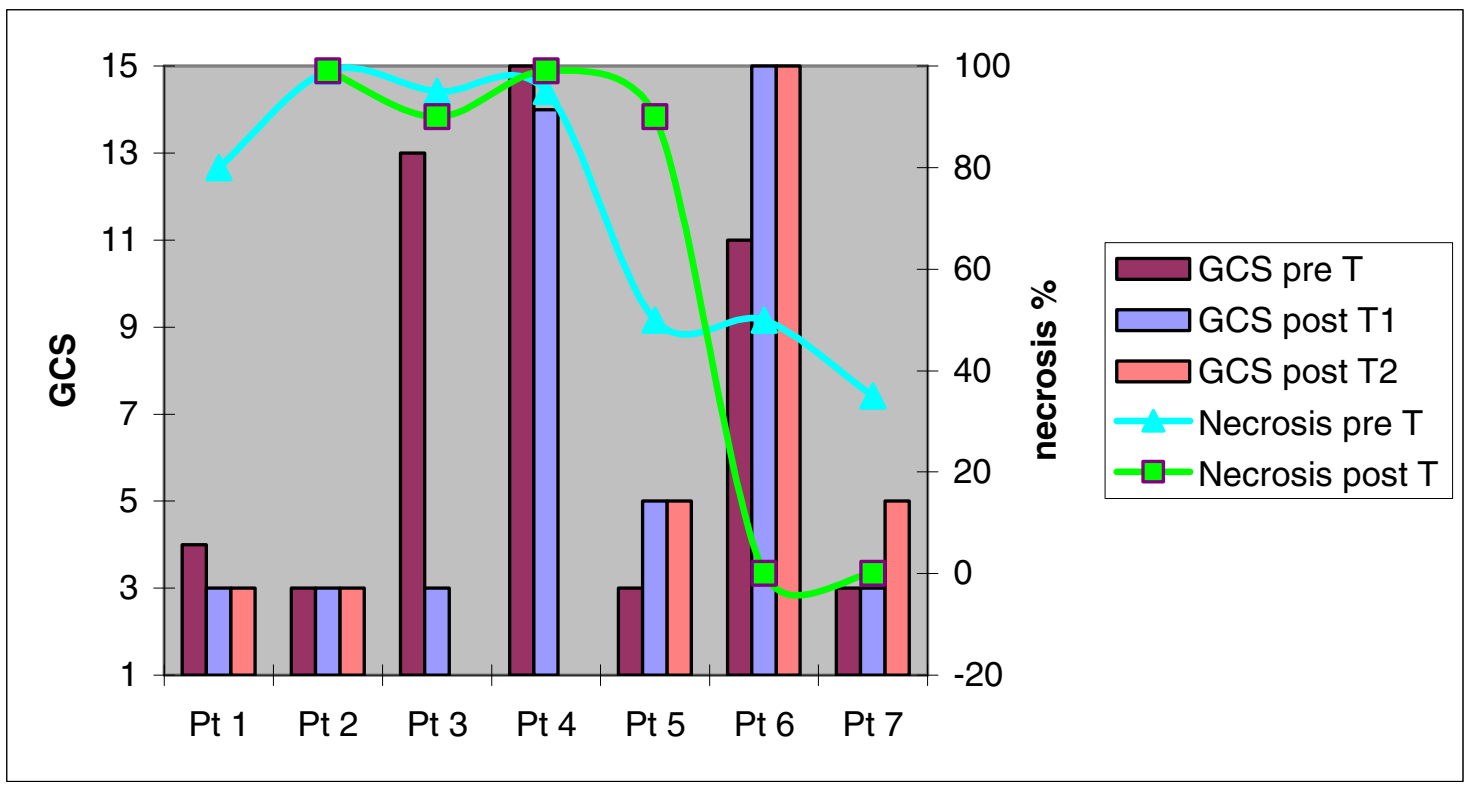

Figure 1. 


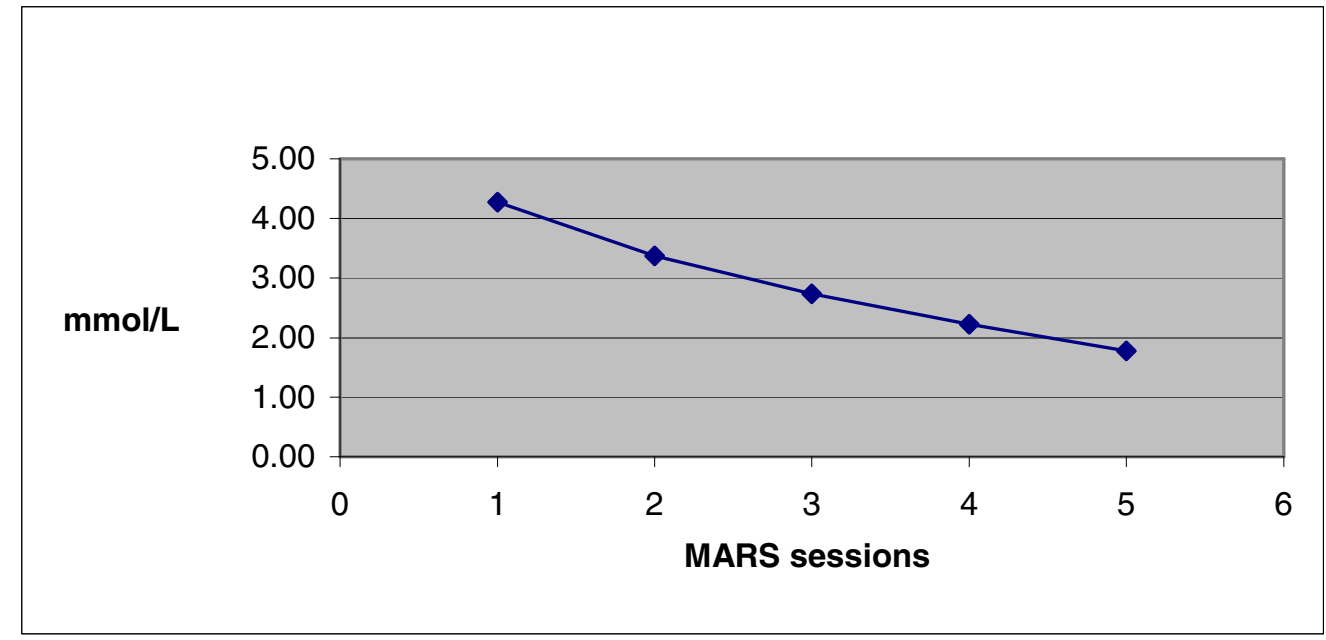

Figure 2. 


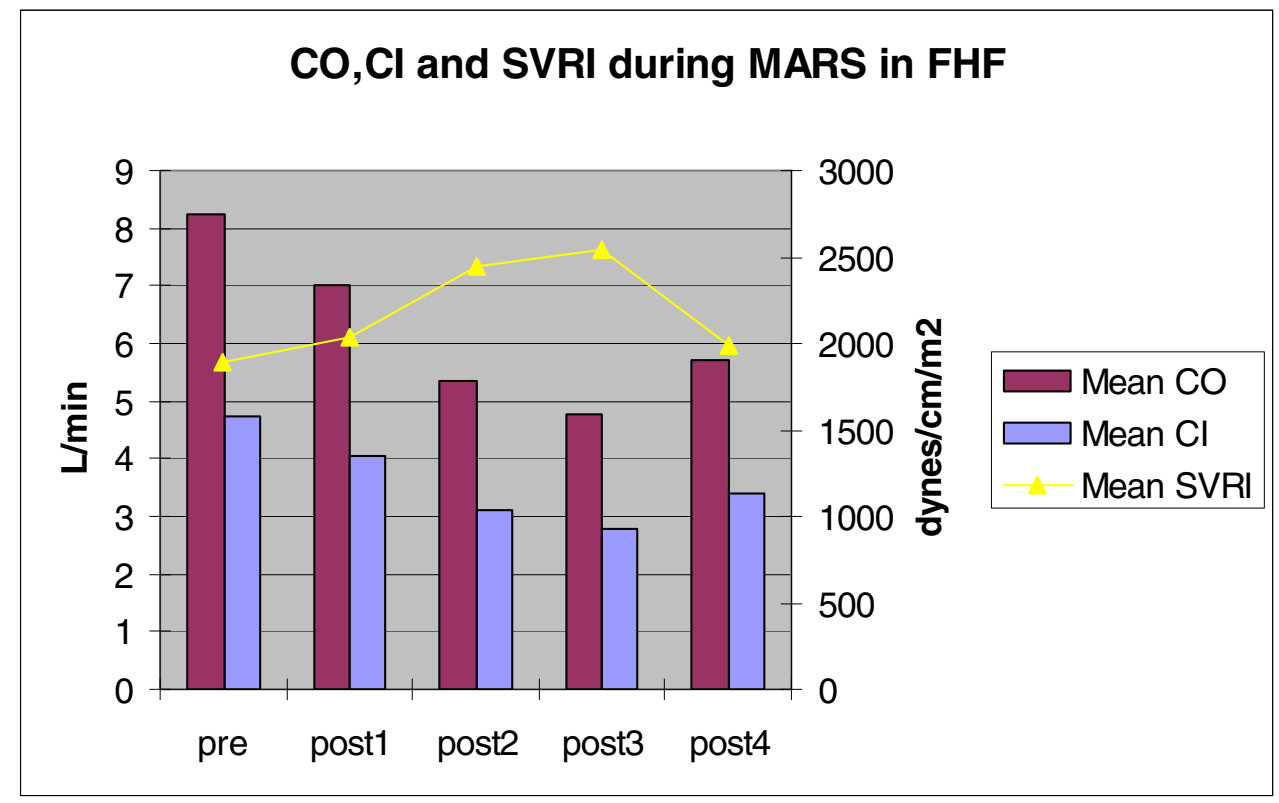

Figure 3. 


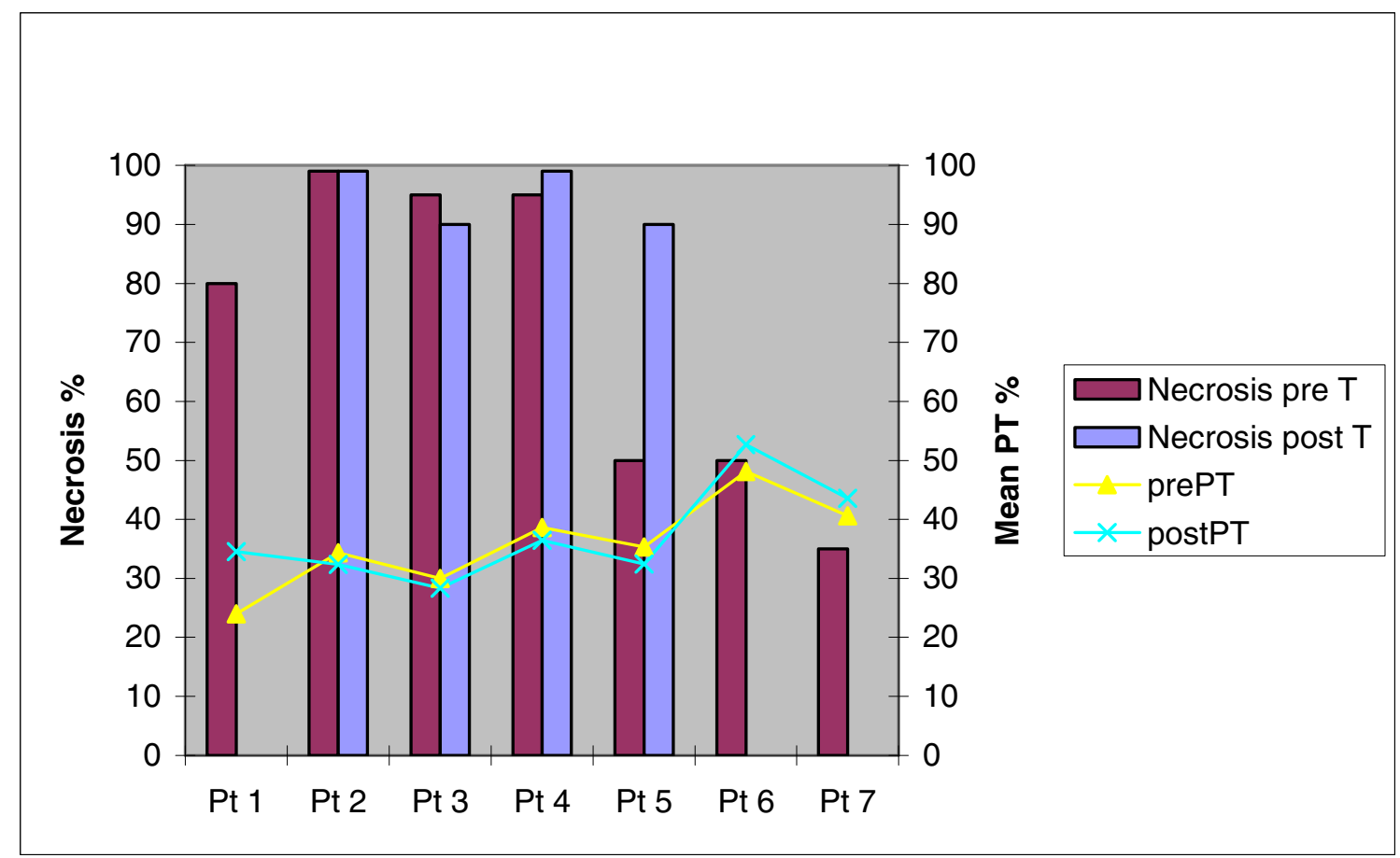

Figure 4. 